\title{
A within-S test of the response specificity of the PRE*
}

\author{
A. GRANT YOUNG, P. A. HALE, and G. D. FUSELIER \\ Louisiana State University, Baton Rouge, Louisiana 70803
}

\begin{abstract}
Sixty-four male albino rats were trained to leverpress in an operant chamber and to run a straight runway. Half of Ss were trained on a continuous reinforcement schedule (CRF), and the other half on a partial reinforcement schedule (PR). Upon completion of acquisition, the groups were subdivided and given acquisition training in the other apparatus, half under conditions of CRF and the other half under conditions of PR. Upon completion of acquisition on both pieces of apparatus, half of Ss in each subgroup were extinguished in the runway, and the other half were extinguished in the operant chamber. Results showed that resistance to extinction of either response was a function only of the training reinforcement for that response, and was independent of the schedule of reinforcement received in training of the other response. Results were discussed in terms of the response specificity of the partial reinforcement effect (PRE).
\end{abstract}

A number of experiments have shown that when an organism is intermittently reinforced (PR) for making a response under one specific set of external stimulus conditions, and continuously reinforced (CRF) for making the same response under a different set of external stimulus conditions, the organism is equally resistant to extinction under either set of external stimuli (Amsel, Rashotte, \& MacKinnon, 1966; Brown \& Logan, 1965; Rashotte \& Amsel, 1968). For example, in an experiment reported by Amsel (1967), rats were run to PR in a black (or white) alley, and to CRF in a white (or black) alley. Results showed that Ss were equally resistant to extinction whether extinction was in both runways or in only one or the other.

These studies are in agreement that within-S organisms, after training as described above, show what has been called the generalized partial reinforcement effect (GPRE), which is to say that PR training increases resistance to extinction under either set of stimulus conditions in spite of the fact that one set of stimuli has been associated with PR and the other set has been associated with CRF.

One theoretical explanation of these results suggests that whatever it is that causes the partial reinforcement effect (PRE) becomes attached in some way (perhaps through classical conditioning) to the proprioceptive feedback produced by the instrumental response. This hypothesis is essentially that of Mowrer (1960) and would predict that in the above experiments, since the same (running) response was made under both sets of external stimulus conditions, and since the PRE was attached to the response-produced stimuli, there should be no difference in resistance to extinction under either set of external stimuli, and all groups should show the GPRE.

This hypothesis is further supported by other experiments (i.e., Young, 1969). In that experiment, rats were trained to leverpress and had PR (or CRF)

\footnotetext{
*This research was supported in part by a grant from the University Council of Research, Louisiana State University, to the first author.
}

associated with an 11-g (or 44-g) lever, and CRF (or PR) associated with a 44-g (or 11-g) lever. Results showed that after 2,000 training trials, $\mathrm{S}$ was significantly more resistant to extinction on the lever weighting which had been associated with PR. Although the same (leverpressing) response was associated with $P R$ and $\mathrm{CRF}$, the response-produced proprioceptive stimuli presumably would be different under PR and CRF conditions.

This hypothesis would predict that when $\mathrm{S}$ receives $P R$ for one response in one situation and receives CRF for a different response in a different situation, $S$ will show the PRE when the response acquired under PR conditions is extinguished, but will not show the GPRE when the response under CRF conditions is extinguished.

The present experiment was thus designed to determine if the PRE will in fact transfer fron one type of response in one experimental situation to a different type of response in a different experimental situation.

\section{METHOD}

\section{Subjects}

The Ss were 64 naive male albino rats, $150-175 \mathrm{~g}$ in weight at the start of the experiment.

\begin{abstract}
Apparatus
One apparatus was a Scientific Prototype operant chamber enclosed in a ventilated sound-insulated cubicle. The operant chamber had a grid floor, and fitted on the end wall was a retractable lever and a foodcup into which the food magazine dispensed 45-mg Noyes food pellets, used as reinforcement.

The other apparatus was a straight Plexiglas runway 63 in. long, $4 \mathrm{in}$. high, and $4 \mathrm{in}$. wide, including the startbox $(63 / 4 \mathrm{in}$. long) and goalbox (10 in. long, and 5-3/8 in. wide). The runway had a grid floor and guillotine doors separated the start and goalboxes from the runway. A Plexiglas retrace door was located 9 in. from the goalbox and fitted on the end wall of the goalbox was a foodcup. Raising the startbox door started a timer, calibrated in $1 / 10$ ths of a second, which was stopped when $S$ cut a photobeam at the entrance to the goalbox.
\end{abstract}

\section{Procedure}

The Ss were randomly selected from the LSU colony and were 
Table 1

Mean Number of Leverpresses in Extinction

\begin{tabular}{lc}
\hline Group & $\begin{array}{c}\text { Mean Number } \\
\text { of Responses }\end{array}$ \\
\hline CC-L & 129.37 \\
CP-L & 134.87 \\
PC-L & 257.87 \\
PP-L & 271.25 \\
\hline
\end{tabular}

placed in individual cages on a food deprivation schedule of $10 \mathrm{~g}$ of Purina Chow every $24 \mathrm{~h}$. Water was available in the cages at all times, and Ss were fed approximately $10 \mathrm{~min}$ after each experimental session.

From Day 4 to Day 8, Ss were handled in pairs for $5 \mathrm{~min}$ each day, and on Days 9-12, Ss were given magazine training on a VI 30-sec schedule. Experimental periods consisted of 20 reinforcements with a reinforcement being one $45-\mathrm{mg}$ Noyes food pellet.

On Day 13, all Ss were conditioned to leverpress, were allowed to make 50 reinforced responses, and on the following day were allowed to make 100 reinforced responses. On Day 15 , Ss were randomly divided into two groups. Group C (continuous reinforcement) received lever training under conditions of CRF, and Group P (partial reinforcement) received lever training under a VR-2 schedule. All Ss were given 100 leverpresses daily for 10 days. A discrete trial procedure was used and the lever, which required $4 \mathrm{sec}$ to retract and extend fully, was inoperative during retraction.

On the day following completion of lever training, Ss began runway training. Each group of Ss was randomly subdivided, creating four treatment groups, CC, CP, PC, and PP. For the group designations, the first letter indicates reinforcement schedule in the operant chamber and the second letter indicates reinforcement schedule in the runway. Thus, Ss in Group CP received continuous reinforcement on the lever and partial reinforcement in the runway. The first 2 days of runway training consisted of five direct placements in the goalbox with a reinforcement of two $45-\mathrm{mg}$ pellets in the foodcup, and on the following day, all Ss made five alley runs under CRF. On the day following, acquisition training began. During acquisition, which consisted of 10 alley runs daily with a 15 -sec intertrial interval, reinforcement was one $45-\mathrm{mg}$ pellet. Acquisition continued for 10 days. For Ss receiving PR runway training, the reinforcement schedule was a VR-2 with the restriction that not more than three consecutive runs be reinforced or nonreinforced.

The order effects of apparatus were balanced in that half of Ss received lever training followed by runway training, and the other half received runway training followed by lever training.

Upon completion of acquisition in both the operant chamber and the runway, the four groups were randomly divided with half of each group receiving extinction in the runway and the other half receiving extinction in the operant chamber. Thus, in extinction, there were eight experimental groups: CC-L, CP-L, PC-L, PP-L, CC-R, CP-R, PC-R, and PP-R. The third letter of the group designation indicates whether extinction was on the lever $(\mathrm{L})$ or in the runway $(\mathrm{R})$.

Table 2

Mean Speed of Responding in Extinction

\begin{tabular}{ccccccc}
\hline & & & & & \multicolumn{1}{c}{$\begin{array}{c}\text { Mean } \\
\text { Ft/Sec }\end{array}$} & $\begin{array}{c}\text { Mean Ft/Sec Per Trial Block } \\
\text { Across } \\
\text { Group }\end{array}$ \\
\cline { 2 - 6 } & 1 & 2 & 3 & 4 & 5 & Blocks \\
\hline CC-R & .61 & .37 & .37 & .41 & .33 & .42 \\
PC-R & .95 & .38 & .29 & .28 & .33 & .45 \\
CP-R & 2.20 & 1.12 & .74 & .57 & .46 & 1.02 \\
PP-R & 1.38 & 1.07 & .83 & .71 & .39 & .88 \\
\hline
\end{tabular}

Extinction sessions on the lever were $15 \mathrm{~min}$ in length and continued for 3 days. Extinction sessions in the runway consisted of 10 runs daily for 5 days. Total latency for 10 trials on each day was recorded. On any trial, if $S$ failed to break the photobeam within $30 \mathrm{sec}$, the timer was stopped, $S$ was removed from the runway and returned to the holding cage to await the next trial, and a latency of $30 \mathrm{sec}$ was recorded. Thus, maximum possible latency for any block of 10 trials was $300 \mathrm{sec}$.

\section{RESULTS AND DISCUSSION}

The total number of leverpresses in extinction in the operant chamber was recorded, and results showed that more responses were made by Group PP-L, followed in order by Groups PC-L, CP-L, and CC-L. These data were subjected to an analysis of variance which showed that the main effect of lever reinforcement schedule was significant beyond the .001 level. The main effect of runway reinforcement schedule and the Runway by Lever interaction were not significant at the .05 level. Thus, Ss which received PR lever training were significantly more resistant to extinction on the lever than were Ss which received CRF lever training, however, runway reinforcement schedule did not affect resistance to extinction on the lever. The mean number of responses for each group in lever extinction is shown in Table 1.

The total latency for each block of 10 trials in the runway was recorded and converted to reciprocals. Results showed that the faster running speed was shown by Group CP-R, followed in order by Groups PP-R, $\mathrm{PC}-\mathrm{R}$, and CC-R. These data were subjected to an analysis of variance with repeated measures which showed that the main effect of runway reinforcement schedule was significant beyond the .001 level. The main effect of lever reinforcement schedule and the Lever by Runway interaction were not significant at the .05 level. Thus, Ss which received PR runway training were significantly more resistant to extinction than were Ss which received CRF runway training; however, lever reinforcement schedule did not affect resistance to extinction in the runway. The main effect of trials was significant beyond the .001 level, and the Trials by Runway reinforcement schedule interaction was significant beyond the .01 level, indicating, respectively, that running speeds decreased across trials, and that PR-trained Ss extinguished significantly more slowly than did CRF-trained Ss. Mean speeds in runway extinction are shown in Table 2.

These data support a theoretical formulation which suggests that the PRE becomes attached in some way to the internal, response-produced stimuli and therefore is specific to the particular instrumental response.

\section{REFERENCES}

Amsel, A. Partial reinforcement effects of vigor and persistence: Advances in frustration theory derived from a variety of within-subjects experiments. In K. W. Spence and J. T. Spence (Eds.), The psychology of learning and motivation: Advances in research and theory. New York: Academic Press, 1967. 
Amsel, A., Rashotte, M. E., \& MacKinnon, J. R. Partial reinforcement effects within subjects and between subjects. Psychological Monographs, 1966, 80(20 Whole No. 628).

Brown, R. T., \& Logan, F. A. Generalized partial reinforcement effect. Journal of Comparative \& Physiological Psychology, $1965,60,64-69$.

Rashotte, M. E., \& Amsel, A. The generalized PRE: Within-S PRF and CRF training in different runways, at different times of day, by different experimenters. Psychonomic Science, $1968,11,315-316$.
Mowrer, O. H. Learning theory and behavior. New York: Wiley, 1960.

Young, A. G. Resistance to extinction as a function of partial reinforcement and bar weighting: A within-Ss design. Journal of Experimental Psychology, 1969, 79, 363-367.

(Received for publication March 14, 1974.)

\title{
Backward masking of gratings varying in spatial frequency*
}

\author{
WILLIAM N. DEMBER, MARY STEFL, and KATHY C. KAO \\ University of Cincinnati, Cincinnati, Ohio 45221
}

\begin{abstract}
Previous research tested the susceptibility to backward masking of disk-shaped targets with varying numbers of internal pie-shaped segments. In general, the greater the number of segments, the harder was the target to detect (spatial forced-choice task) and also the harder to mask. Furthermore, certain targets were unmaskable and the detectability of others was enhanced by the masking stimulus (a black ring). The present experiment tested the generality of those findings using, as targets, disks with internal segments comprising gratings varying in spatial frequency; the earlier results were generally replicated, except that there was little evidence of backward enhancement.
\end{abstract}

In previous research, we uncovered a target variable with considerable impact on visual backward masking. The variable was suggested by Werner's (1935) observation that targets with internal contours are less susceptible to masking than are homogeneous targets, presumably because the former have greater figural strength. Our initial experiment (Sherrick \& Dember,

\footnotetext{
* Supported by Grant GB 33621 from the National Science Foundation to William N. Dember. Reprints should be requested from William N. Dember, Department of Psychology, University of Cincinnati, Cincinnati, Ohio 45221.
}

1970) employed disk-shaped targets which were black on one side of the diameter and white on the other; we thought of them as having one internal contour. Such targets did prove harder to mask (by a black ring) than homogeneous black disks.

To determine whether there was a quantitative relation between susceptibility to masking and number of internal contours, we again employed disk-shaped targets that were half black and half white. Number of internal contours was manipulated by varying the number of pie-shaped alternating black and white 